\title{
Open Thoracic Surgery for Removal of a Two-Year-Old Impacted Esophageal Coin
}

\author{
Isaac Okyere 1,2,3*, Samuel Gyasi Brenu1, Perditer Okyere ${ }^{2,3,4}$ \\ ${ }^{1}$ Cardiovascular and Thoracic Surgery Unit, Department of Surgery, Kumasi, Ghana \\ ${ }^{2}$ School of Medicine and Dentistry, College of Health Sciences, Kwame Nkrumah University of Science, Kumasi, Ghana \\ ${ }^{3}$ Komfo Anokye Teaching Hospital, Kumasi, Ghana \\ ${ }^{4}$ Renal Unit, Department of Medicine, Kumasi, Ghana \\ Email:*drokyere@yahoo.com
}

How to cite this paper: Okyere, I., Brenu, S.G. and Okyere, P. (2020) Open Thoracic Surgery for Removal of a Two-Year-Old Impacted Esophageal Coin. Open Journal of Thoracic Surgery, 10, 32-40. https://doi.org/10.4236/ojts.2020.101004

Received: December 27, 2019

Accepted: February 25, 2020

Published: February 28, 2020

Copyright $\odot 2020$ by author(s) and Scientific Research Publishing Inc. This work is licensed under the Creative Commons Attribution International License (CC BY 4.0).

http://creativecommons.org/licenses/by/4.0/ (c) (i) Open Access

\begin{abstract}
Introduction: Esophageal foreign bodies are important and serious cause of morbidity and mortality in both children and adults, usually as a result of serious complications, such as perforation, necrosis, mediastinitis, and fistulation. Therefore, rapid and accurate diagnosis with subsequent removal is very important. Clinical Case: We present and discuss the presentation, diagnosis and surgical management of a 6-year-old with a 2-year history of ingested coin locked in the oesophagus. Discussion: Diagnosis was established by upper gastrointestinal endoscopy, barium swallow and chest $\mathrm{x}$-ray. The coin was removed by open surgery via oesophagotomy through right thoracotomy after failed retrieval via rigid oesophagoscopy. Conclusion: Surgical treatment in the form of esophagotomy via thoracotomy may be necessary in some cases of impacted foreign bodies in the esophagus where endoscopic removal is unsuccessful.
\end{abstract}

\section{Keywords}

Foreign Body, Esophagus, Retrieval, Thoracotomy, Coin

\section{Introduction}

Foreign esophageal bodies are common finding across all age groups but are particularly found to be predominant among paediatric population with a peak age range of 3 months to 6 years, the exploratory period of every child with the tendency to put anything into the mouth [1] [2] [3] [4]. It has similar predilections for both males and females [2]. As found in this patient, in children, the most common foreign body ingested has been reported in several literatures to 
be coins, but several other objects such as disc batteries, toys, magnets, toy parts, safety pins and screws have also been retrieved [1] [2] [3] [5] [6]. In the adult and elderly population, commonly ingested foreign bodies are fish bones and dentures respectively, though meat chunks causing oesophageal impaction have also been reported [1] [6]. Foreign body ingestion in adults is commonly seen in patients with some form of psychiatric illness, alcoholics or among prison in-mates [7]. Chaudhry and friends reported a case of an impacted lithobezoar in the distal oesophagus of a 54-year man with a prior history of psychiatric illness [8].

\section{Case Report}

Patient is a 6-year-old boy who accidentally swallowed a coin about 2 years prior to presentation and has been subsequently experiencing dysphagia to solids for a year associated with occasional vomiting and regurgitation but no odynophagia, hematemesis, heartburns or retrosternal chest pain. He was having recurrent non-productive cough for which a recent episode was reviewed at a peripheral hospital where a chest $\mathrm{x}$-ray done showed what seems to be a coin in the thoracic oesophagus. Patient was then referred to the ENT surgeon for endoscopic removal. However, attempted removal by rigid endoscopy by the ENT surgeon was unsuccessful due to visualization of an obstruction at $16 \mathrm{~cm}$ from the incisors embedded in inflammatory tissue associated with mucosal bleeding on attempted retrieval. Therefore the patient was referred to cardiothoracic surgery for possible retrieval by open surgery.

Cardiothoracic surgery review found a patient who was generally clinically stable with unremarkable examination findings. As shown in Figure 1, the chest $\mathrm{x}$-ray done showed a circular radio-opaque foreign body of about $2 \mathrm{~cm}$ in diameter lodged in the posterior mediastinum at the level of T4. Barium study of the oesophagus showed the circular foreign body at the level of T4 with constriction of the oesophagus at T4 with proximal dilatation as shown in Figure 2. However, there was no loss of continuity of the lumen of the oesophagus. All laboratory investigations done were within normal ranges. The patient was then prepared

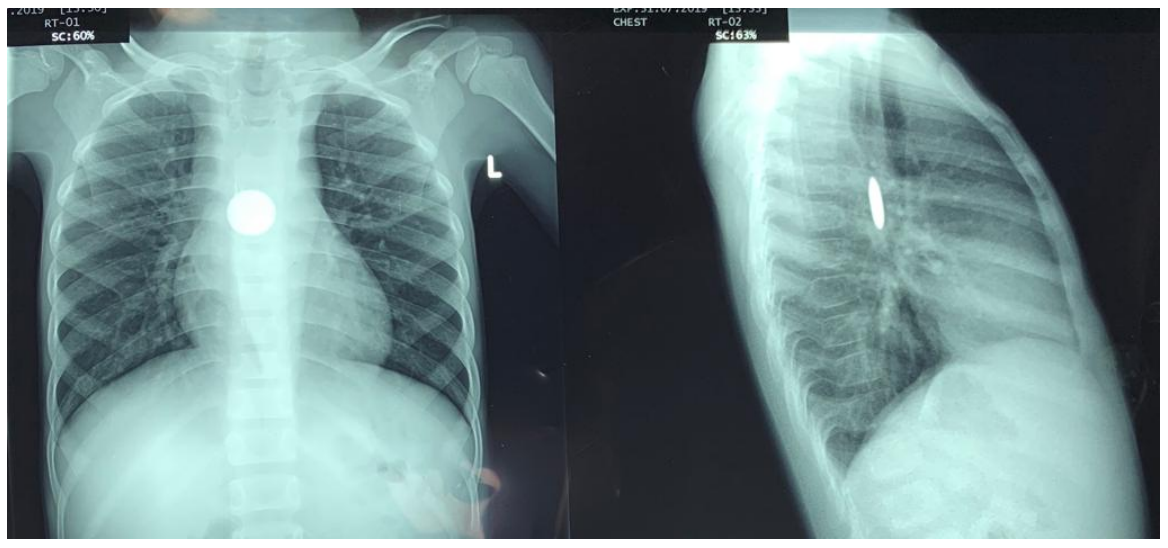

Figure 1. Chest X-ray showing the coin at the level of the bifurcation of the trachea. 


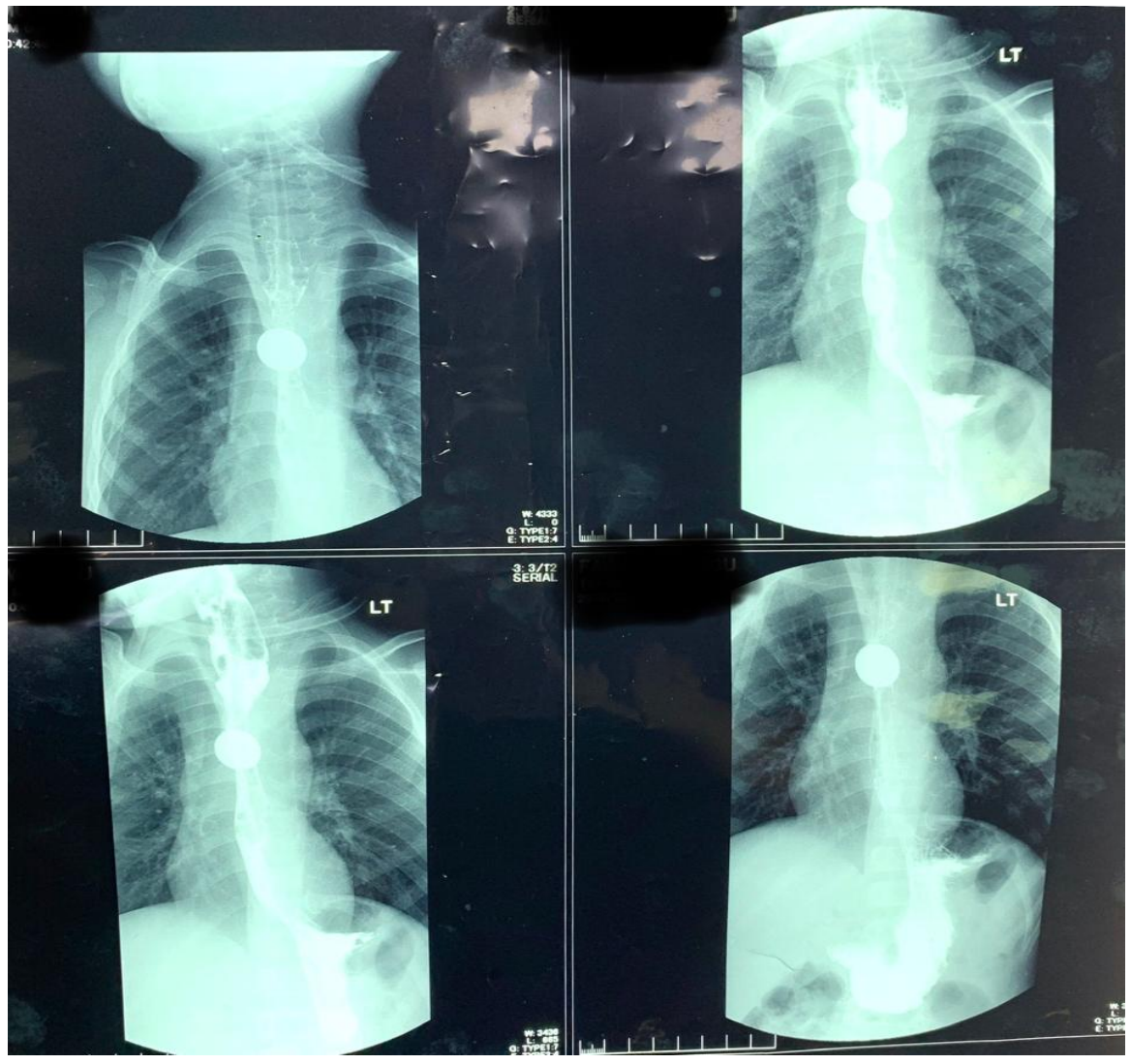

Figure 2. Barium swallow showing the rounded opacity (the coin) without any fistulation.

for esophagotomy and removal of the foreign body via right thoracotomy after written informed consent was obtained from parents.

In theatre, the patient was positioned in the left lateral decubitus position and under aseptic conditions and general anaesthesia, a standard right posterolateral thoracotomy was done entering the $5^{\text {th }}$ pleural bed. Esophageal dissection and isolation done to isolate the mid-oesophagus and a $3 \mathrm{~cm}$ oesophagotomy made longitudinally to expose the foreign body. A coin which was found to be extensively corroded was retrieved whole as shown in Figure 3 and Figure 4. The lumen was lavaged copiously with diluted povidine-iodine and the oesophagotomy repaired in a single-layered interrupted fashion with vicryl 3/0 after passing a nasogastric tube as shown in Figure 5. The chest was then closed over a size $20 \mathrm{Fr}$ chest tube in layers after haemostasis and warm saline irrigation. Post-operative chest $\mathrm{x}$-ray showed normal findings as shown Figure 6.

The postoperative period was uneventful and the patient was kept nil per os with nasogastric tube in situ for 7 days. He was on intravenous antibiotics, fluid, analgesia and parenteral nutrition. Oral sips were initiated on post-operative day 7 which was well tolerated and was on normal diet by day 10. Nasogastric tube was removed on post-operative day 8 and patient subsequently discharged. Patient has been stable 6 months after surgery without any complications. 


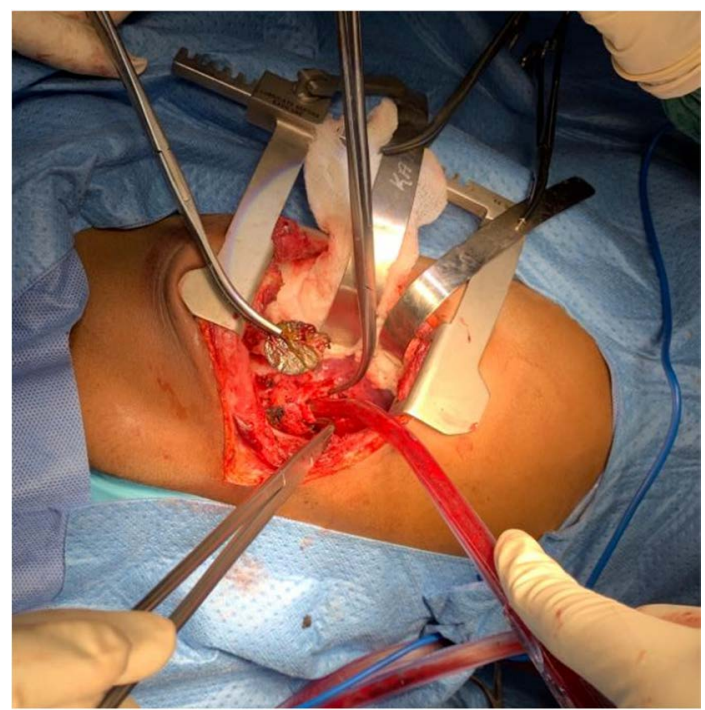

Figure 3. Intraoperative findings at right thoracotomy showing the rusted coin.

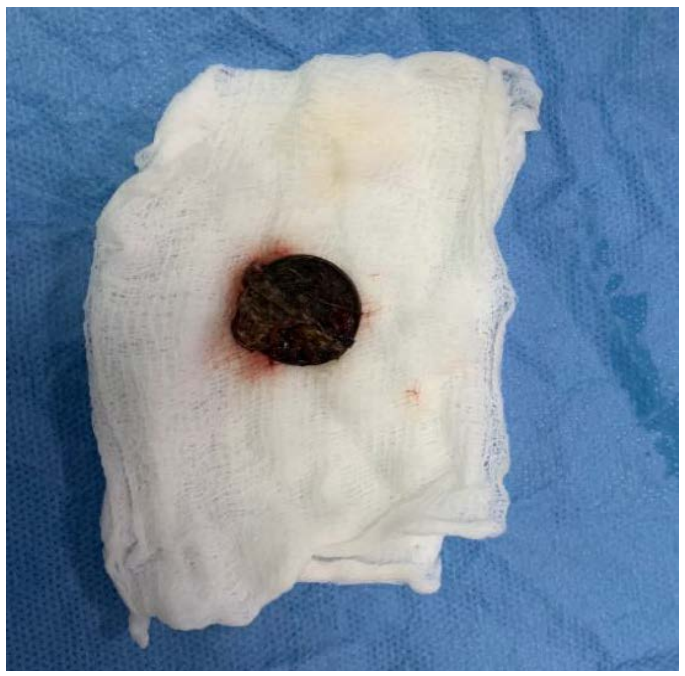

Figure 4. The rusted coin.

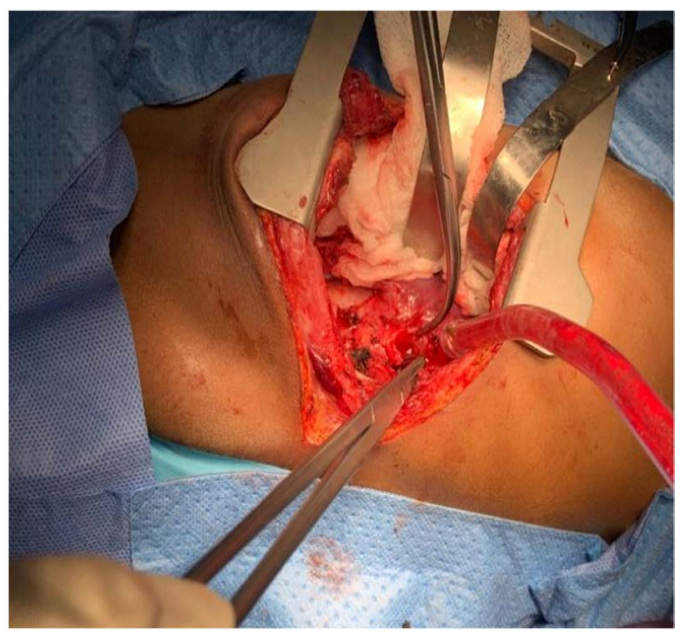

Figure 5. Intraoperative findings at right thoracotomy showing the repaired esophagotomy. 


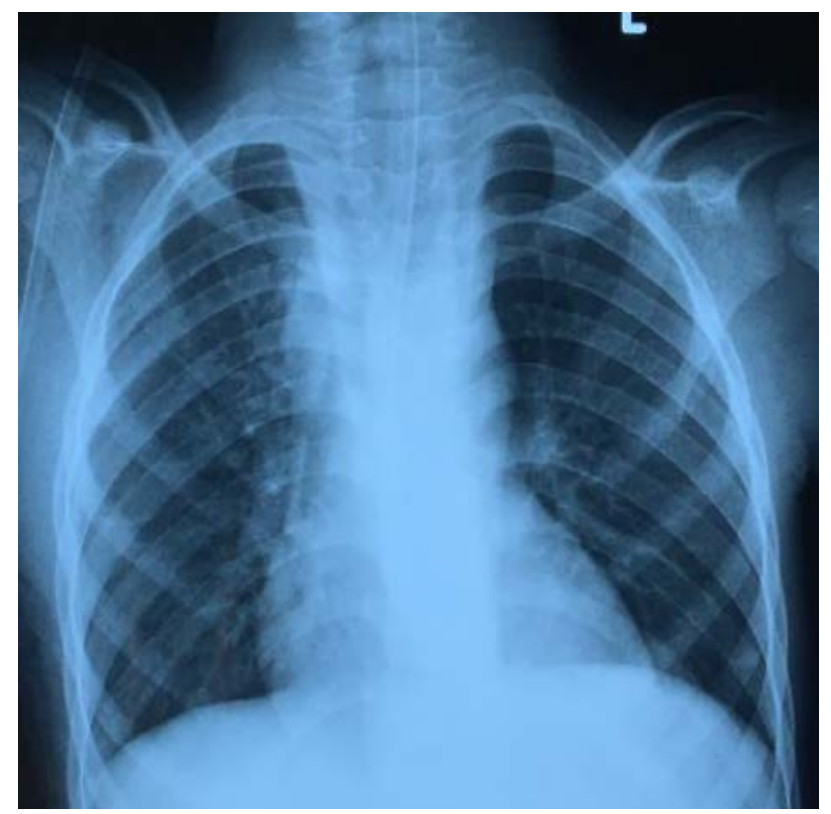

Figure 6. Postoperative chest $\mathrm{x}$-tray.

\section{Discussion}

Impaction of foreign bodies in the oesophagus usually occurs due to the presence points of luminal narrowing along the length of the oesophagus which may be anatomical or pathological. Anatomically, the oesophageal constrictions found at the cricopharyngeal junction in the proximal oesophagus, aortic arch or left main bronchus in the mid-oesophagus and the diaphragmatic hiatus in the distal oesophagus serve as potential locations for impaction of ingested foreign bodies. The coin got lodged up at the mideosophagus in our case at the level of T4. Oesophageal diseases causing stenosis, such as strictures and atresiae, and dysmotility disorders such as achalasia could also cause obstruction to the descent of an ingested foreign body [9]. This was well highlighted in the study by Lin and friends where about $26 \%$ of elderly with foreign body impaction had an underlying oesophageal abnormality [10].

Multiple case reports have documented variable durations of impaction of foreign body. Several literatures report of cases with durations of impaction ranging between few hours to about a week [3] [5] [6] [7]. Miller et al. reported from a retrospective review that only $4 \%$ of foreign body impactions had at least a week between ingestion and diagnosis [11]. Tashtush and colleagues reported of a 36-month old baby who had a 26 months history of chronic oesophageal foreign body before diagnosis [12], this is similar to our case who had the impacted coin stayed for two years.

\subsection{Clinical Presentation}

Foreign body ingestions mostly traverse the alimentary canal and are expelled spontaneously in most cases. However, in cases where there is impaction along the tract, the associated symptom is chiefly dysphagia in over $90 \%$ of 
cases [3] [5] [6] [9] as noticed in our case who presented with dysphagia to solids and was tolerating only liquids. Other associated symptoms include odynophagia, hypersalivation, vomiting, regurgitation, retrosternal chest or neck pain and occasionally stridor and dyspnoea in the event of tracheal compression [6] [9].

Complications associated with ingestion of foreign bodies, though rare, usually arise from pressure necrosis causing leakage of oesophageal content and damage to surrounding structures [5]. Possible complications of oesophageal foreign body impaction include perforation and mediastinitis, tracheoesophageal fistula, aorto-oesophageal fistula, retropharyngeal abscess, pneumomediastinum, pneumothorax and hydrothorax [3] [5] [9]. The risk of developing complications also depends on the nature of the ingested foreign body. Sharp objects have the tendency of causing perforations and oesophageal leak or fistula formation while batteries may contain corrosive contents which could cause chemical burns of the mucosa and extend transmurally to involve surrounding structures [3] [5].Our patient had no complications on presentation.

Foreign body impaction most commonly occurs at the cricopharyngeal junction due to it being the narrowest part of the oesophagus. However, the other points of oesophageal narrowing also contribute significantly to foreign body impaction [4] [13] as was noted in this report where the impaction was at the level of T4, another point of narrowing in the decent of the oesophagus in the thoracic cavity.

\subsection{Diagnostic Evaluation}

Radiological evaluation is paramount so as to initially confirm the presence of the radio-opaque foreign body, determine exact location and number, plan the approach for removal and also to determine the occurrence of complications such as pneumomediastinum or involvement of surrounding soft tissues or organs [4] [9] [13]. Radio-opaque objects are easily diagnosed on radiological biplanar films, be it x-ray or CT scan while radiolucent objects such as meat or food bolus may be easily missed unless it contains cartilage or some bones [9]. CT scans are useful to determine possible involvement of surrounding structures or to further evaluate if endoscopy yields negative results as was seen in the case report by Tashtush and associates [4] [12].

Endoscopy is important in the management of oesophageal foreign body impaction since it is of both diagnostic and therapeutic importance. Diagnostic value of endoscopy is particularly paramount when clinical and radiological evaluations are inconclusive [9]. An alternative to esophagoscopy is a barium oesophagogram [14]. This patient underwent rigid upper gastrointestinal oesophagoscopy and attempted retrieval but removal of the coin was not successful and it was associated with bleeding. He later had barium oesophagogram as shown in Figure 2 showing the rounded foreign body with no fistulation. An earlier chest $\mathrm{x}$-ray as shown in Figure 1 had equally shown the rounded foreign body. 


\subsection{Management}

Most foreign bodies that are able to traverse the span of the oesophagus usually are passed out uneventfully. However, options for management of impacted foreign bodies are endoscopic removal and surgical retrieval [13] if spontaneous passage does not occur. The first-line option for foreign body retrieval is rigid or flexible esophagoscopy done under general anaesthesia [12]. Lin et al. reported a success rate of $88.8 \%$ in the utilization of endoscopy for oesophageal foreign body retrieval with an associated complication rate of $13.3 \%$. The documented complications were bleeding and oesophageal perforation [10]. Altokhais and colleagues also reported a success rate of $86 \%$ for removal via esophagoscopy [4]. Our patient had unsuccessful removal via rigid esophagoscopy and associated bleeding as a complication and therefore the reason for referral to the cardiothoracic surgery unit for possible surgical removal.

In the event that endoscopic retrieval is impossible, the best option is surgical approach especially in the presence of life-threatening complications or anticipation of their occurrence if approached endoscopically [12] [13]. A review of 9 published papers by Cianci et al. showed that endoscopic failure to retrieve the foreign body was a paramount indication for surgical intervention [9] similar to our case.

The approach to surgical removal depends on the site of impaction as seen on evaluation. Cervical esophageal impactions are managed surgically via a transcervical esophagotomy while mid-esophageal impactions are approached via a right thoracotomy due to the rightward deviation of the oesophagus [9]. The study by Chaudhry and colleagues reported of a distal esophageal foreign body that was surgically retrieved via a left posterolateral thoracotomy [8]. Our patient had a successful right thoracotomy for the coin retrieval due to location at the mideosophagus. As shown in Figure 3 and Figure 4, the impacted coin was found to be rusted.

\section{Conclusion}

Surgical treatment in the form of esophagotomy via thoracotomy may be necessary in some cases of impacted foreign bodies in the esophagus where endoscopic removal is unsuccessful. Whereas coins are visible on chest radiographs, dentures are radiolucent most of the time and chest $\mathrm{x}$-rays are not helpful in detection.

\section{Acknowledgements}

Written informed consent was obtained from the parents for publication of the case and accompanying images and we are grateful to the theatre staff at the Accident and Emergency centre.

\section{Conflicts of Interest}

The authors declare no conflicts of interest regarding the publication of this paper. 


\section{References}

[1] Sharma, K., Duggal, K.K. and Miglani, H.P. (1999) An Unusual Impacted Foreign Body Oesophagus in an Infant. Indian Journal of Otolaryngology and Head \& Neck Surgery, 51, 77-79.

[2] Saadeh, C. and Ulualp, S.O. (2018) An Uncommon Source for Oesophageal Foreign Body: Fidget Spinner. SAGE Open Medical Case Reports, 6, 2050313 X1878122. https://doi.org/10.1177/2050313X18781229

[3] Obateru, O.A., Durowaye, M.O., Olokoba, A.B. and Olaniyi, O.K. (2016) Endoscopic Removal of Impacted Oesophageal Foreign Body: A Case Report and a Review of Literature. Vol. 13, African Journal of Paediatric Surgery, 13, 41-43. http://www.ncbi.nlm.nih.gov/pubmed/27251523 https://doi.org/10.4103/0189-6725.181706

[4] Altokhais, T.I., Al-Saleem, A., Gado, A., Al-Qahtani, A. and Al-Bassam, A. (2017) Esophageal Foreign Bodies in Children: Emphasis on Complicated Cases. Asian Journal of Surgery, 40, 362-366. https://doi.org/10.1016/j.asjsur.2015.12.008

[5] Majola, N.F., Kong, V.Y., Mangray, H., Govindasamy, V., Laing, G.L. and Clarke, D.L. (2018) An Audit of Ingested and Aspirated Foreign Bodies in Children at a University Hospital in South Africa: The Pietermaritzburg Experience. South African Medical Journal, 108, 205-209. https://doi.org/10.7196/SAMJ.2018.v108i3.12590

[6] Chua, Y.K.D., See, J.Y. and Ti, T.K. (2006) Oesophageal-Impacted Denture Requiring Open Surgery. Singapore Medical Journal, 47, 820-821.

[7] Yaliwal, V.G., Hegde, H.V., Arunkumar, J.S., Garag, S.S. and Raghavendra Rao, P. (2014) Foreign Body Oesophagus: The Case of a Missing Second Coin. Indian Journal of Anaesthesia, 58, 364-365. https://doi.org/10.4103/0019-5049.135098

[8] Chaudhry, I., Asban, A., Kazoun, R. and Khurshid, I. (2013) Lithobezoar, a Rare Cause of Acute Oesophageal Obstruction: Surgery after Failure of Endoscopic Removal. BMJ Case Reports, 2013, 1-3. https://doi.org/10.1136/bcr-2013-008984

[9] Cianci, P., Tartaglia, N., Altamura, A., di Lascia, A., Fersini, A., Neri, V., et al. (2018) Cervical Esophagotomy for Foreign Body Extraction: A Case Report and Extensive Literature Review of the Last 20 Years. American Journal of Case Reports, 19, 400-405. https://doi.org/10.12659/AJCR.908373

[10] Lin, H.C., Chen, C.J., Lin, H.H., Huang, J.T. and Chen, M.J. (2013) Endoscopic Treatment of Esophageal Foreign Bodies in the Elderly. International Journal of Gerontology, 7, 35-39. https://doi.org/10.1016/j.ijge.2012.05.003

[11] Miller, R.S., Willging, J.P., Rutter, M.J. and Rookkapan, K. (2004) Chronic Esophageal Foreign Bodies in Pediatric Patients: A Retrospective Review. International Journal of Pediatric Otorhinolaryngology, 68, 265-272. https://www.sciencedirect.com/science/article/abs/pii/S0165587603003707 https://doi.org/10.1016/j.ijporl.2003.09.021

[12] Tashtush, N.A., Bataineh, Z.A., Yusef, D.H., Al Quran, T.M., Rousan, L.A., Khasawneh, R., et al. (2019) Ingested Sharp Foreign Body Presented as Chronic Esophageal Stricture and Inflammatory Mediastinal Mass for 113 Weeks: Case Report. Annals of Medicine and Surgery, 45, 91-94. https://doi.org/10.1016/j.amsu.2019.07.028

[13] Mallick, F.R., Sahota, R.S., Elloy, M.D. and Conboy, P.J. (2014) A Rare Case of Foreign Body Impaction Requiring Oesophagotomy. Annals of the Royal College of Surgeons of England, 96, 11-13.

https://doi.org/10.1308/003588414X13814021678998 
[14] Singh, A., Bajpai, M., Panda, S.S., Chand, K., Jana, M. and Ali, A. (2014) Oesophageal Foreign Body in Children: 15 Years Experience in a Tertiary Care Paediatric Centre. African Journal of Paediatric Surgery, 11, 238-241.

http://www.ncbi.nlm.nih.gov/pubmed/25047316

https://doi.org/10.4103/0189-6725.137333 